\title{
Effect of Vaginal Low Dose Sildenafil on the Outcome of ICSI after ICSI Failures Attributed to Poor Endometrial Development
}

\author{
Huda T. Madkour, Yahia A. Wafa, Ahmed S. Amer
}

Department of Obstetrics and Gynecology, Faculty of Medicine, Al-Azhar University, Cairo, Egypt

Corresponding author: Huda T. Madkour, Mobile: (+20) 01141122600

\begin{abstract}
Background: Endometrial thickness is a marker of endometrial receptivity and a prognostic factor for embryo transfers (ET). Poor endometrium is a multifactorial condition; so, its management should be cause-related. One of the treatment options is Sildenafil citrate intake. It causes uterine vascularity improvement.

Objectives: The aim of the current work was to evaluate the effects of vaginally administered doses of sildenafil on endometrial lining and ICSI outcome in infertile women with poor endometrial development.

Patients and Methods: This study included a total of thirty infertile women with at least one prior ICSI failure attributed to inadequate endometrial development, undergoing ICSI procedure attending at a private assisted reproductive center. All patients underwent ICSI using a long GnRH-a protocol with the addition of sildenafil vaginal suppositories ( $20 \mathrm{mg}, 4$ times per day) for 10 days beginning with ovulation induction and continued until trigger day. Results: The results showed that increased endometrial thickness due to treatment with sildenafil to reach $12-14 \mathrm{~mm}$ in 28 out of 30 cases and was associated with a pregnancy rate of $60.7 \%$ if compared to the same group thickness. Also, another effect of sildenafil citrate was increasing the endometrial trilaminar pattern in 27 case and subsequently with high pregnancy rate.
\end{abstract}

Conclusion: Increased endometrial thickness due to sildenafil therapy was associated with high pregnancy rat and its intake was associated with increased trilaminar endometrial pattern in $90 \%$ of patients which causes high pregnancy rate.

Keywords: Sildenafil, ICSI, Endometrial.

\section{INTRODUCTION}

The release of nitric oxide leads to the relaxation of smooth vascular muscles through cyclic guanosine mono-phosphate (cGMP) (1). Endothelial and inducible nitric oxide synthase isoforms have been identified in the vascular endothelium of endometrium and the myometrium (2). Phosphodiesterase hydrolyzes cyclic nucleotides, such as cGMP. Specific PDE subtypes inhibitors augment the effects of cyclic nucleotides on target tissues ${ }^{(3)}$. Sildenafil citrate is 5-specific PDE inhibitor that increase the vasodilator effects of nitric oxide on vascular smooth muscle. Sildenafil achieved more and more success to improve male erectile diseases many years ago ${ }^{(4)}$. Efforts to improve endometrium during IVF by estrogens and/or low dose aspirin have met with different success degrees ${ }^{(5)}$. Interest has focused on sildenafil citrate as a modulator of uterine vascularity ${ }^{(6)}$. In fact Sher and Fisch ${ }^{(7)}$, reported that vaginally sildenafil suppositories are able to improve uterine vascularity and endometrial thickness in females with previous recurrent IVF failure attributed to weak endometrial development ${ }^{(5)}$. Nitric oxide and cGMP are needed for good vascular function ${ }^{(8)}$.

Improvement in endothelial function has been observed after sildenafil treatment by increasing endothelial progenitor cells and some growth factors (9). Endothelial progenitor cells develop into mature ones during repair of endothelial damage ${ }^{(10)}$.Sildenafil being a vasodilator, decreases pulsatility index of uterine artery so increases endometrial thickness subsequently increases the endometrial receptivity ${ }^{(11)}$. Large clinical trials are needed to determine the therapeutic effect of Viagra in different groups of infertile women with poor endometriosis (12).

The aim of the current work was to evaluate the effects of vaginally administered doses of sildenafil on endometrial lining and ICSI outcome in infertile women with poor endometrial development.

\section{PATIENTS AND METHODS}

This study included a total of thirty infertile women undergoing ICSI procedure attending at a private assisted reproductive center. Approval of the ethical committee and a written informed consent from all the subjects were obtained. This study was conducted between June 2018 till December 2018. All patients underwent ICSI using a long GnRH-a protocol with the addition of sildenafil vaginal suppositories ( $20 \mathrm{mg}$, 4 times per day) for 10 days beginning with ovulation induction and continued until trigger day.

Inclusion criteria:

- The age should be less than 40 years old.

- Primary infertility patients who would proceed to ICSI with previous IVF failure due to Poor endometrium.

- A minimum of two good quality embryos available for transfer. 


\section{Exclusion criteria}

- Male factor of infertility.

\section{Statistical analysis}

Recorded data were analyzed using the statistical package for social sciences, version 20.0 (SPSS Inc., Chicago, Illinois, USA). Quantitative data were expressed as mean \pm standard deviation (SD). Qualitative data were expressed as frequency and percentage.

\section{The following tests were done:}

- Independent-samples t-test of significance was used when comparing between two means.

- Chi-square $\left(\mathrm{x}^{2}\right)$ test of significance was used in order to compare proportions between two qualitative parameters.

- The confidence interval was set to $95 \%$ and the margin of error accepted was set to $5 \%$. The pvalue was considered significant as the following:

- Probability (P-value)

- P-value <0.05 was considered significant.

- P-value <0.001 was considered as highly significant.

P-value $>0.05$ was considered insignificant.

\section{RESULTS}

Endometrial thickness (EMT) at time of ET with use of sildenafil.

Table (1): Effect of sildenafil on endometrial thickness at time of ET

\begin{tabular}{|c|c|c|}
\hline Endometrial thickness & $\mathbf{N}$ & $\mathbf{\%}$ \\
\hline $12-14 \mathrm{ml}$ & 28 & 93.3 \\
\hline $7-10 \mathrm{ml}$ & 2 & 6.7 \\
\hline Total & 30 & 100 \\
\hline
\end{tabular}

Table (1) shows percentages of patients who their endometrial thickness became adequate and those with poor thickness at time of ET. All took sildenafil. 93.3\% of cases included in the study their endometrial thickness reached to $12 \_14 \mathrm{ml}$ at time of ET which is adequate thickness for ET.

Table (2): Endometrial thickness (EMT) at time of ET with use of sildnafil and its effect on clinical pregnancy occurrence.

\begin{tabular}{|c|c|c|c|c|}
\hline \multirow{3}{*}{$\begin{array}{c}\text { Clinically } \\
\text { pregnant }\end{array}$} & \multicolumn{4}{|c|}{ Thickness } \\
\cline { 2 - 5 } & $\begin{array}{c}(12-14 \mathrm{ml}) \\
(\mathrm{n}=28)\end{array}$ & \multicolumn{1}{c|}{$\mathrm{ml})(\mathrm{n}=2)$} \\
\cline { 2 - 5 } & $\mathrm{N}$ & $\%$ & $\mathrm{~N}$ & $\%$ \\
\hline Yes & 17 & 60.7 & 0 & 0 \\
\hline No & 11 & 39.3 & 2 & 100 \\
\hline Total & 28 & 100 & 2 & 100 \\
\hline Chi $^{2}$ & \multicolumn{4}{|c|}{2.802} \\
\hline P value & \multicolumn{4}{|c|}{0.094} \\
\hline
\end{tabular}

Table (2) shows 30 cases on sildenafil as an adjuvant therapy, 28 of them their endometrial thickness reached $12-14 \mathrm{ml}$ at time of ET and 17 cases of these 28 cases $(70.6 \%)$ became clinically pregnant. Endometrial pattern at time of ET with use of sildenafil and its effect in clinical pregnancy occurrence.

Table (3): Endometrial pattern at time of ET with use of sidenafil

\begin{tabular}{|c|c|c|}
\hline Endometrial pattern & $\mathbf{N}$ & $\mathbf{\%}$ \\
\hline Homogenous & 3 & 10 \\
\hline Multilayer & 27 & 90 \\
\hline Total & 30 & 100 \\
\hline
\end{tabular}

Table (3) shows effects of sildenafil on endometrial pattern (as 27 case out of 30 ones included in the study developed trilaminar endometrial pattern at time of ET)

Table (4): Endometrial pattern with sildenafil and its effect on incidence of clinical pregnancy

\begin{tabular}{|c|c|c|c|c|}
\hline \multirow{3}{*}{$\begin{array}{l}\text { Clinically } \\
\text { pregnant }\end{array}$} & \multicolumn{4}{|c|}{ Endometrial pattern } \\
\hline & \multicolumn{2}{|c|}{$\begin{array}{l}\text { Homogenous } \\
\qquad(\mathrm{n}=3)\end{array}$} & \multicolumn{2}{|c|}{$\begin{array}{c}\text { Multilayer } \\
n=27)\end{array}$} \\
\hline & $\mathrm{N}$ & $\%$ & $\mathrm{~N}$ & $\%$ \\
\hline Yes & 0 & 0 & 17 & 63 \\
\hline No & 3 & 100 & 10 & 37 \\
\hline Total & 3 & 100 & 27 & 100 \\
\hline$\overline{\mathrm{Chi}^{2}}$ & \multicolumn{4}{|c|}{4.362} \\
\hline$P$ value & \multicolumn{4}{|c|}{$0.037 *$} \\
\hline
\end{tabular}

Table (4) shows that 27 cases of the 30 cases of our study developed trilaminar endometrial pattern at time of ET and 17 of these 27 cases (i.e 63\%) got clinically pregnant with $\mathrm{p}$-value 0.037 which is significant statistically.

\section{DISCUSSION}

At its inception, Intracytoplasmic sperm injection was one of the most exciting technological advances in assisted reproductive technology. This technique quickly turned into the routine practice of fertility centers around the world ${ }^{(\mathbf{1 3})}$.

implantation failures are due to a lot of maternal factors as uterine abnormalities, metabolic or hormonal disorders, infections, immunological factors, thrombophilia and others. Severe male factor cannot be neglected due to its impact on the embryo genetics. There are other new factors as cumulus cells contribution ${ }^{(14)}$.our inability to understand causes of bad endometrial receptivity resulted in many suggestions of inefficient adjuvant empirical therapies (15).

Inadequate endometrial receptivity causes two- thirds of implantation failures ${ }^{(16)}$. Accumulated 
evidence has suggested that there is an endometrial receptivity alteration in females with unexplained RIF and also before IVF aura suggesting the endometrial significance for females with unexplained RIF ${ }^{(17)}$. endometrial thickness have been considered as good predictive parameter of endometrial receptivity and a prognostic factor for embryo transfers during IVF/ICSI cycles ${ }^{(\mathbf{1 8 )}}$.

It is known that adequate endometrial thickness is necessary for a successful conception and several studies have found low conception rates associated with poor endometrium. EMT less than $7 \mathrm{~mm}$ on ultrasound is inefficient for embryo transfer. Weak endometrium remains a problem in reproductive science with only few reasonable results obtained of the currently trials with adjuvant therapies ${ }^{(19)}$.

Thin endometrium management should depend on its cause and aim for endometrial receptivity improvement ${ }^{(20)}$. Sildenafil citrate is one of treatment options as it causes an improvement in uterine blood flow and, if taken with estrogen, could cause the estrogen-induced endometrial improvement ${ }^{(\mathbf{2 1})}$.

In the present study, sildenafil was effective in increasing endometrial thickness in the vast majority of cases; 28 out of 30 patients developed reasonably thick endometrial with high pregnancy rate.

It has been shown previously that vaginal sildenafil citrate is effective for the treatment of women with repeated implantation failure and leads to increase endometrial thickness and attaining pregnancy in women with poor endometrial growth (22).

Takasaki et al. evaluated sildenafil effect on improving radial arteries flow. He found that Sildenafil citrate increased radial artery-resistance index and endometrial thickness in $92 \%$ cases $^{(23)}$.

In our study, sildenafil citrate increased the triple line pattern of the endometrium in 27 patients (90\%). The pregnancy rate in these patients was $63 \%$, while it was $0 \%$ in those with homogenous endometrium.

A combined analysis of endometrial thickness and pattern on the day of trigger proved to be a better predictor of IVF/ICSI outcome than a single parameter analysis ${ }^{(24)}$.

Yaman et al. ${ }^{(25)}$ found that endometrial volume and thickness on trigger date did not predict pregnancy occurrence. However, endometrial volume of $2.5 \mathrm{~mL}$ appeared to favor pregnancy.

\section{Conclusions}

It could be concluded that increased endometrial thickness as a result of sildenafil therapy was associated with a pregnancy rate of $60.7 \%$ of these with same thickness group. Endometrium volume was increased due to sildenafil treatment. Administration of sildenafil citrate was associated with increased triple line pattern of the endometrium in $90 \%$ of patients which lead to a pregnancy rate was $63 \%$, compared to $0 \%$ in patients with homogenous endometrium

\section{RECOMMENDATIONS}

1. Evaluation of implantation failure after ICSI should include diagnostic hysteroscopy, and evaluation of the endometrium with $2 \mathrm{D}$ and $3 \mathrm{D}$ ultrasonography.

2. Thin endometrium should be treated before ICSI cycles irrespective of failures in previous IVF trials.

3. For improving the condition of the endometrium regarding its thickness and pattern, and uterine blood flow, sildenafil administration is recommended as an effective therapy.

4. Sildenafil can be probably administered through the vaginal route, as $20 \mathrm{mg}$ suppositories 4 times per day. A 10-day course from the day of ovulation induction administration is recommended for thickening of the endometrium in cases with thin endometrium.

5. We recommend the use of safe analgesic such as paracetamol to ease the headaches if caused by sildenafil due to its vasodilator effect.

6. Control group is needed to facilitate outcome evaluation and to compare it with patients group to determine if good results occurred due to sildenafil or not related??

7. We recommend further research to be done in this matter as different populations and larger sample as these may change our opinions about safety and efficacy of sildenafil.

\section{REFERENCES}

1.Ballard SA, Gingell CJ, Tang K et al. (1998): Effects of Sildenafil on the relaxation of human corpus cavernosum tissue in vitro and on the activities of cyclic nucleotide phosphodiesterase isoenzymes. J Urol., 159:2164-71.

2.Telfer JF, Irvine GA, Kohnen G et al. (1997): Expression of endothelial and inducible nitric oxide synthase in non-pregnant and decidualized human endometrium. Mol Hum Reprod., 3:69-75.

3. Fisch JD, Behr B and Conti M (1998): Enhancement of motility and acrosome reaction in human spermatozoa: differential activation by type-specific phosphodiesterase inhibitors. Hum Reprod., 5:1248-54.

4. Boolell M, Gepi-Attee S, Gingell JC et al. (1996): Sildenafil, a novel effective oral therapy for male erectile dysfunction. Br J Urol., 78:257-61.

5.Sher G, Dodge S, Maassarani G et al. (1993): Management of suboptimalsonographic endometrial patterns in patients undergoing in vitro fertilization and embryo transfer. Hum Reprod., 8:374-9.

6. Cameron IT, Cambell S (1998): Nitric oxide in the endometrium. Hum Reprod Update, 4:565-9. 
7.Sher G, Fisch JD (2002): Effect of vaginal sildenafil on the outcome of in vitro fertilization (IVF) after multiple IVF failures attributed to poor endometrial development. Fertility and Sterility, 78(5): 1073-1076.

8. Khalil RA, Crews JK, Novak J et al. (1998): Enhanced vascular reactivity during inhibition of nitric oxide synthesis in pregnant rats. Hypertension, 31:1065-9.

9. Foresta C, Caretta N, Lana A et al. (2007): Relationship between vascular damage degrees and endothelial progenitor cells in patients with erectile dysfunction: effect of vardenafil administration and PDE5 expression in the bone marrow. Eur Urol., 51: 1411-7.

10.Hristov M, Weber C (2008): Endothelial progenitor cells in vascular repair and remodeling. Pharmacol Res., 58:148-51.

11. Das V, Agarwal A, Pandey A et al. (2009): Evaluation of role of sildenafil in improving IUI success rates. International Journal of Gynecology \& Obstetrics, 107: 413-729.

12. Goswamy RK, William G and Steptoe PC (1988): Decreased uterine perfusion: a cause of infertility. Hum Reprod., 3:955-9.

13. Rubino $P$, Viganò $P$, Luddi A et al. (2016): The ICSI procedure from past to future: a systematic review of the more controversial aspects. Human Reproduction Update, 22(2): 194-227.

14.Benkhalifa M, Demirol A, Sari T et al. (2012): Autologous embryo-cumulus cells co-culture and blastocyst transfer in repeated implantation failures: a collaborative prospective randomized study. Zygote, 20(2):173-80.

15. Valdes CT, Schutt A and Simon C (2017): Implantation failure of endometrial origin: it is not pathology, but our failure to synchronize the developing embryo with a receptive endometrium. Fertil Steril., 108(1):15-8.

16.Shi C, Shen H, Fan LJ et al. (2017): Endometrial MicroRNA Signature during the Window of Implantation Changed in Patients with Repeated Implantation Failure. Chin Med J., 130(5): 566-73.
17.Li TC, Klentzeris L, Barratt C et al. (1993): A study of endometrial morphology in women who failed to conceive in a donor insemination programme. BJOG., 100(10):935-8.

18. Yuan X, Saravelos SH, Wang Q et al. (2016): Endometrial thickness as a predictor of pregnancy outcomes in 10787 fresh IVF-ICSI cycles. Reproductive Biomedicine Online, 33(2): 197-205.

19. Eftekhar M, Sayadi $M$ and Arabjahvani F (2014): Transvaginal perfusion of G-CSF for infertile women with thin endometrium in frozen ET program: A nonrandomized clinical trial. Iranian Journal of Reproductive Medicine, 12(10): 661-666.

20.Lebovitz O, Orvieto R (2014): Treating patients with "thin" endometrium - an ongoing challenge. Gynecol Endocrinol., 30(6):409-14.

21.Sher G, Fisch JD (2002): Effect of vaginal sildenafil on the outcome of in vitro fertilization (IVF) after multiple IVF failures attributed to poor endometrial development. Fertility and Sterility, 78(5): 1073-1076.

22. Dehghani Firouzabadi R, Davar R, Hojjat F et al. (2013): Effect of sildenafil citrate on endometrial preparation and outcome of frozen-thawed embryo transfer cycles: a randomized clinical trial. Iranian Journal of Reproductive Medicine, 11(2): 151-158.

23. Takasaki A, Tamura H, Miwa I et al. (2010): Endometrial growth and uterine blood flow: a pilot study for improving endometrial thickness in the patients with a thin endometrium. Fertility and Sterility, 93(6): 18511858 .

24. Chen SL, Wu FR, Luo C et al. (2010): Combined analysis of endometrial thickness and pattern in predicting outcome of in vitro fertilization and embryo transfer: a retrospective cohort study. Reprod Biol Endocrinol., 8:30.

25. Yaman C, Ebner T, Sommergruber M et al. (2000): Role of three-dimensional ultrasonographic measurement of endometrium volume as a predictor of pregnancy outcome in an IVF-ET program: A preliminary study measurement. Fertil Steril., 74:797-801. 